\title{
A Non-Parametric Approach for Performance Appraisal of Agricultural Market Committees in India
}

\author{
E. S. V. Narayana Rao ${ }^{1}$ and A. A. Chari ${ }^{2}$ \\ ${ }^{1}$ Assistant Professor \& Head, Dept. of Statistics \& Computer Applications, Ag. College, \\ MAHANANDI-518502, A.P., India. \\ 2. Dean of Physical Sciences, Rayalaseema University, Kurnool, A.P., India.
}

\begin{abstract}
Efficient performance of Agricultural Market Committees (AMCs) is considered to be the sine quo non for the economic development of an agrarian country like India. Though the number of AMCs has been steadily increasing in India, still the farmers are being exploited by one form or another in transacting the agricultural commodities. In view of this, several apprehensions and concerns were raised fearing about the performance of $A M C s$ in discharging the regulatory provisions for efficient transaction of agricultural commodities. Various enactments have been formulated by Government from time to time to revamp the agricultural marketing system in the country and presently, Model act 2005 (The State Agricultural Produce Marketing (Development and Regulation) Act, 2005) has been under implementation. In this context of exploring the agricultural marketing system with a farmers ended approach, the present paper aims at analyzing the performance appraisal of AMCs in Coastal region of AP in India through Data Envelopment Analysis(DEA) approach. The analytical findings revealed that $53 \%$ of selected AMCs are being operated at Scale Efficiency $<1$. The remaining $47 \%$ AMCs are being operated at constant return to scale (CRS) and this directs the Government to continue the existing support even in the future.
\end{abstract}

Keywords: Agricultural Market Committees, Data Envelopment Analysis, Efficiency, Return to Scale.

\section{Introduction}

Efficient performance of agricultural markets is considered as the sine qua non of economic development of any country. This is not an exception with reference to India. It is a known fact that, regulated agricultural markets have been established in India with the prime objective of transacting agricultural produce efficiently and thereby, to safeguard the interests of the farming community. Since 1966 and upto the current year, there have been a steady progress in the establishment of regulated agricultural markets in the country. In India, the organized marketing of agricultural commodities has been promoted through a network of regulated markets. Most State Governments and Union Territory(UT) administrations have enacted legislations (Agricultural Produce Marketing (Regulation) Act (APMC Act)) to provide for the regulation of agricultural produce markets. While by the end of 1950, there were 286 regulated markets in the country, their number as on $31^{\text {st }}$, March 2011 stood at 7566 consists of 2433 principal markets and 5133 sub-yards. Some wholesale markets are outside the purview of the regulation under APMC Acts. Similar trends were noticed in the state of Andhra Pradesh in general and Coastal region of Andhra Pradesh in particular. In Andhra Pradesh, with 23 districts, there are 905 regulated markets which consists of 329 principal markets and 576 sub-yards and in Coastal region of Andhra Pradesh comprising of 9 districts, 127 principal markets and 360 sub-yards are reported as on $31^{\text {st }}$, March 2011.

So far, so forth, these regulated markets in Coastal region of Andhra Pradesh are serving the farming community in view of the laid out promises at the time of their establishment. The contributions of these regulated markets are clearly manifested through various outcomes in the forms of viz, regulating the marketing practices, systematizing the marketing costs, settlement of disputes between farmers and traders, prompt payment of sales proceeds, checking the malpractices of marketing middlemen etc., with a view to safeguard the interests of the farmers in transacting their produce and inturn, to realize significant producer's share in consumer's rupee. To keep up these promises, the Government from time to time revised the marketing regulations and presently Model Act, 2005 (The State Agricultural Produce Marketing (Development and Regulation) Act, 2005) has been enacted to make the farmers more dynamic and competitive in the context of liberalized trade regime. However, in reality, there exists a wide gap between the promises made and actual performance shown by these regulated markets. The earlier mentioned regulatory provisions offered by these regulated markets are being exploited in one form or other against the interests of the farming community. Thus, it became evident that, these regulated markets in the Coastal region of Andhra Pradesh in India are not able to function efficiently in discharging the regulatory provisions and hence, the farmers could not enjoy the true benefits of market regulation. It is in this context, the researchers made an attempt to analyse the technical efficiency in the functioning of regulated markets in Coastal region of Andhra Pradesh in India. It has seen that 
not many attempts were found in India in general and Coastal region in particular to analyse the efficiency of functions of regulated markets. In this background, this study is certainly a contribution in the analysis of efficiency of regulated markets. Thus this study explores the use of Data Envelopment Analysis(DEA), a nonparametric approach which is a powerful Operations Research tool appropriate for the context. This study is conducted with the following specific objectives:

1) To study whether the regulatory provisions contribute to the technical efficiency of the functioning of regulated markets, and if they contribute, how they influence the efficiency.

2) To analyse the trends in the efficiency in the functioning of regulated markets.

\section{Methodology}

For analyzing the efficiency of regulated markets in India, Coastal region of Andhra Pradesh state has been purposefully selected, as the investigators hail from this state. Data Envelopment Analysis (DEA) model was used to assess the technical efficiency of regulated markets in Coastal region of Andhra Pradesh in India.

DEA is one of the most popular non-parametric approaches used in the literature to appraise the performance of Decision Making Units (DMUs). It permits the selection of efficient markets with in the Coastal region. DEA was used in prior studies on the efficiency of financial institutions to examine the impact of some specific changes such as financial reforms, the impact of financial practices and the impact of different ownership groups. DEA assesses the efficiency frontier on the basis of all input and output information from the region. (Rogers, 1998). Thus, the relative efficiency of markets operating in the same region can be estimated (Fried et al. 2002). Hence, identification of performance indicators in regulated markets is useful for identifying a benchmark for the whole region. Moreover, the DEA methodology has the capacity to analyse multi-inputs and multi-outputs to assess the efficiency of institutions (Coelli, Rao \& Battese 1998).

DEA Model :

Several DEA models have been presented in the literature. The basic DEA model evaluates efficiency based on the productivity ratio which is the ratio of outputs to inputs. This study applied Charnes, Cooper and Rhode's (CCR) (1978) model and Banker, Charnes and Cooper (BCC) (1984) model. The production frontier has constant returns to scale in CCR model. The basic CCR model formulation (dual problem/ envelopment form) is given by:

The basic CCR model formulation (dual problem/ envelopment form) :

$\operatorname{Min} \theta-\varepsilon\left(\sum_{i=1}^{m} s_{i}^{-}+\sum_{r=1}^{s} s_{r}^{+}\right)$

Subject to :

$$
\begin{array}{cc}
\sum_{j=1}^{n} \lambda_{j} x_{i j}+s_{i}^{-}=\theta x_{i 0} & (\mathrm{i}=1, \ldots \ldots \ldots, \mathrm{m}) \\
\sum_{j=1}^{n} \lambda_{j} y_{r j}-s_{r}^{+}=y_{r 0} \quad(\mathrm{r}=1, \ldots \ldots \ldots \ldots, \mathrm{s}) \\
\lambda_{j} \geq 0 & (\mathrm{j}=1, \ldots \ldots \ldots \ldots, \mathrm{n})
\end{array}
$$

Source :Zhu (2003, p.13)

where, $\boldsymbol{\theta}$ denotes the efficiency of DMUj , while $y_{r j}$ is the amount of $r^{\text {th }}$ output produced by DMU $j$ using $x_{i j}$ amount of $i^{\text {th }}$ input. Both $y_{r j}$ and $x_{i j}$ are exogenous variables and $\lambda_{j}$ represents the benchmarks for a specific DMU under evaluation (Zhu 2003). Slack variables are represented by $s_{i}$ and $s_{r}$. According to Cooper, Seiford and Tone (2004) the constraints of this model are :

i. the combination of the input of firm $j$ is less than or equal to the linear combination of inputs for the firm on the frontier;

ii. the output of firm $j$ is less than or equal to the linear combination of inputs for the

firm on the frontier; and

iii. the main decision variable $\boldsymbol{\theta}_{j}$ lies between one and zero.

Further, the model assumes that all DMUs are operating at an optimal scale. However, imperfect competition and constraints to finance may cause DMUs to operate at some level different to the optimal scale (Coelli, Rao \& Battese 1998). Hence, the Banker, Charnes and Cooper (1984) BCC model is developed with a production frontier that has variable returns to scale. The BCC model forms a convex combination of DMUs (Coelli, Rao \& Battese 1998). Then the constant returns to scale linear programming problem can be modified to one with variable returns to scale by adding the convexity constraint $\Sigma \lambda_{j}=1$. The model given below illustrates the basic $\mathrm{BCC}$ formulation (dual problem/envelopment form) :

The basic BCC model formulation (dual problem/envelopment form) : 
$\operatorname{Min} \theta-\varepsilon\left(\sum_{i=1}^{m} s_{i}^{-}+\sum_{r=1}^{s} s_{r}^{+}\right)$

Subject to :

$$
\begin{aligned}
& \sum_{j=1}^{n} \lambda_{j} x_{i j}+s_{i}^{-}=\theta x_{i 0} \quad(\mathrm{i}=1, \ldots \ldots \ldots . ., \mathrm{m}) \\
& \sum_{j=1}^{n} \lambda_{j} y_{r j}-s_{r}^{+}=y_{r 0} \quad(\mathrm{r}=1, \ldots \ldots \ldots ., \mathrm{s}) \\
& \lambda_{j} \geq 0 \quad(\mathrm{j}=1, \ldots \ldots \ldots \ldots, \mathrm{n}) \\
& \sum_{j=1}^{n} \lambda_{j}=1
\end{aligned}
$$

Source :Zhu (2003, p.13)

This approach forms a convex hull of intersecting planes (Coelli, Rao \& Battese 1998). These planes envelop the data points more tightly than the constant returns to scale (CRS) conical hull. As a result, the variable returns to scale (VRS) approach provides technical efficiency (TE) scores that are greater than or equal to scores obtained from the CRS approach (Coelli, Rao \& Battese 1998). Moreover, VRS specifications will permit the calculation of TE decomposed into two components: scale efficiency (SE) and pure technical efficiency (PTE). Hence, this study first uses the CCR model to assess TE then applies the BCC model to identify PTE and SE for each DMU. The relationship of these concepts is given below :

Relationship between TE, PTE and SE :

$\mathrm{TE}_{\mathrm{CRS}}=\mathrm{PTE}_{\mathrm{VRS}} * \mathrm{SE}$

where $\quad \mathrm{TE}_{\mathrm{CRS}}=$ Technical efficiency of constant return to scale

$\mathrm{PTE}_{\mathrm{VRS}}=$ Technical efficiency of variable return to scale $\mathrm{SE}=$ Scale efficiency

Source : Coelli, et al., (1998).

The above relationship, which is unique, depicts the sources of inefficiency, i.e., whether it is caused by inefficient operation (PTE) or by disadvantageous conditions displayed by the scale efficiency (SE) or by both. If the scale efficiency is less than 1, the DMU will be operating either at decreasing return to scale (DRS) which implies if a proportional increase of all input levels produces a less-than-proportional increase in output levels or increasing return to scale (IRS) which is the converse case. This can lead to a conclusion that resources may be transferred from DMUs operating at DRS to those operating at IRS to increase average productivity at both sets of DMUs (Boussofiane et al.,1992).

\section{Data And Variables For The Study}

Efficiency of a AMC depends on the facilities available with the AMC such as drying platforms, storage units, market functionaries etc., which leads to good amount of arrivals and in turn AMC earns countable market fees creating employment. DEA assumes that, the inputs and outputs have been correctly identified. Usually as the number of inputs and outputs increase, more DMUs tend to get an efficiency rating of 1 as they become too specialized to be evaluated with respect to other units. On the other hand, if there are too few inputs and outputs, more DMUs tend to be comparable. In any study, it is important to focus on correctly specifying inputs and outputs. DEA is commonly used to evaluate the efficiency of a number of AMCs and it is a multi-factor productivity analysis model for measuring the relative efficiency of a homogeneous set of regulated markets (DMUs). For every inefficient AMC, DEA identifies a set of corresponding efficient AMC that can be utilized as benchmarks for improvement of performance and productivity. DEA is developed based on two scale of assumptions viz., Constant Return to Scale (CRS) model and Variable Return to Scale (VRS) model. CRS means that the producers are able to linearly scale the inputs and outputs without increasing or decreasing efficiency. This is a significant assumption. The assumption of CRS may be valid over limited ranges but its use must be justified. As an aside, CRS tends to lower the efficiency scores while VRS tends to raise efficiency scores.

For enabling the study of evaluation of AMC's we have the following resources(inputs) and productivity indicators or outputs :

Inputs : $X_{1}$ - Arrivals(in Qtls), $X_{2}$ - Amenities \& facilities(in MTs.), $X_{3}$ - Market functionaries(in Nos.),

$\mathrm{X}_{4}$ - Notified market area(in Kms)

Outputs : $Y_{1}$ - Valuation(Rs. in Lakhs), $Y_{2}-$ Market fees(Rs. in Lakhs), $Y_{3}-$ Staff position(in Nos.) 
The study involves the application of DEA to assess the efficiency of 127 AMCs in Coastal region, with nine districts of Andhra Pradesh State in India during the years 2005-06, 2006-07, 2007-08 and 2008-09. The data used for assessment was obtained from the Annual Reports published by Directorate of Marketing and Inspection(vide ref : www.agmarknet.nic.in) and from the Annul Administrative Reports of the selected AMCs. DEA is applied separately for each year using input-orientation with radial distances to the efficient frontier. By running these programmes with the same data under CRS and VRS assumptions, measures of overall technical efficiency (TE) and 'pure' technical efficiency(PTE) are obtained, along with scale efficiencies. The details were shown in Tables (5) to (7).

\section{Results And Discussions}

The main theme of the present study is to assess the performance of AMCs in nine districts viz., East Godavari, Guntur, Krishna, Nellore, Prakasham, Srikakulam, Vijayanagaram, Visakapatnam, West Godavari which are located in Coastal region of Andhra Pradesh state in India. The study intends to assess the efficiency of facilities in AMCs and thereby improving operations of AMCs to provide suitable and improved marketing avenues for farming community.

PERFOMANCE OF Amcs AT REGIONAL LEVEL: The findings of DEA portrayed through Table 1 revealed the following salient information:

$>\quad$ Nearly 47 percent i.e. 60 out of 127 total AMCs in Coastal region are operated at Constant Return to Scale(CRS) in the entire period of study, that is 2005-06 to 2008-09. This reveals that these 60 AMCs in Coastal region are operating with stability, balancing the inputs(resources contained in these) to satisfy the outputs i.e. the purpose of AMCs. These are :

Table 1 : AMCs with constant return to scale (CRS) :

\begin{tabular}{|c|c|c|c|c|c|}
\hline \multirow{2}{*}{ S.No. } & \multirow{2}{*}{ Name of AMC } & \multicolumn{4}{|c|}{ RETURN TO SCALE } \\
\hline & & $2005-06$ & 2006-07 & $2007-08$ & $2008-09$ \\
\hline 1 & ALAMURU & crs & crs & crs & crs \\
\hline 2 & AMBAJIPETA & crs & crs & crs & crs \\
\hline 3 & JAGGAMPETA & crs & crs & crs & crs \\
\hline 4 & KAKINADA & crs & crs & crs & crs \\
\hline 5 & PEDDAPURAM & crs & crs & crs & crs \\
\hline 6 & PITHAPURAM & crs & crs & crs & crs \\
\hline 7 & RAJOLE & crs & crs & crs & crs \\
\hline 8 & Ramachandrapuram & crs & crs & crs & crs \\
\hline 9 & SAMARLAKOTA & crs & crs & crs & crs \\
\hline 10 & SAMPARA & crs & crs & crs & crs \\
\hline 11 & TALLAREVU & crs & crs & crs & crs \\
\hline 12 & DUGGIRALA & crs & crs & crs & crs \\
\hline 13 & GUNTUR & crs & crs & crs & crs \\
\hline 14 & KUCHINAPUDI & crs & crs & crs & crs \\
\hline 15 & PIDIGURALLA & crs & crs & crs & crs \\
\hline 16 & ROMPICHERLA & crs & crs & crs & crs \\
\hline 17 & TADIKONDA & crs & crs & crs & crs \\
\hline 18 & AVANIGADDA & crs & crs & crs & crs \\
\hline 19 & GANNAVARAM & crs & crs & crs & crs \\
\hline 20 & KAIKALUR & crs & crs & crs & crs \\
\hline 21 & KANCHIKACHERLA & crs & crs & crs & crs \\
\hline 22 & MALLESWARAM & crs & crs & crs & crs \\
\hline 23 & VIJAYAWADA & crs & crs & crs & crs \\
\hline 24 & ATMAKUR & crs & crs & crs & crs \\
\hline 25 & GUDUR & crs & crs & crs & crs \\
\hline 26 & KAVALI & crs & crs & crs & crs \\
\hline 27 & KOVVUR & crs & crs & crs & crs \\
\hline 28 & NELLORE & crs & crs & crs & crs \\
\hline 29 & SULLUR PET & crs & crs & crs & crs \\
\hline 30 & VAKADU & crs & crs & crs & crs \\
\hline 31 & VENKATAGIRI & crs & crs & crs & crs \\
\hline 32 & DARSI & crs & crs & crs & crs \\
\hline 33 & GIDDALUR & crs & crs & crs & crs \\
\hline 34 & KANDUKUR & crs & crs & crs & crs \\
\hline 35 & KANIGIRI & crs & crs & crs & crs \\
\hline 36 & MARKAPUR & crs & crs & crs & crs \\
\hline 37 & ONGOLE & crs & crs & crs & crs \\
\hline 38 & PARCHUR & crs & crs & crs & crs \\
\hline
\end{tabular}




\begin{tabular}{|l|l|l|l|l|l|}
39 & ICHAPURAM & crs & crs & crs & crs \\
\hline 40 & KOTABOMMALI & crs & crs & crs & crs \\
\hline 41 & SRIKAKULAM & crs & crs & crs & crs \\
\hline 42 & TEKKALI & crs & crs & crs & crs \\
\hline 43 & BOBILLI & crs & crs & crs & crs \\
\hline 44 & GAJAPATHINAGARAM & crs & crs & crs & crs \\
\hline 45 & KURUPAM & crs & crs & crs & crs \\
\hline 46 & PUSUPATHIREGA & crs & crs & crs & crs \\
\hline 47 & VIJAYANAGARAM & crs & crs & crs & crs \\
\hline 48 & ANAKAPALLI & crs & crs & crs & crs \\
\hline 49 & BHEEMUNEPATNAM & crs & crs & crs & crs \\
\hline 50 & CHINTHAPALLI & crs & crs & crs & crs \\
\hline 51 & VISAKAPATNAM & crs & crs & crs & crs \\
\hline 52 & ACHANTA & crs & crs & crs & crs \\
\hline 53 & AKIVIDU & crs & crs & crs & crs \\
\hline 54 & BHEMADOLU & crs & crs & crs & crs \\
\hline 55 & BHIVARAM & crs & crs & crs & crs \\
\hline 56 & DENDLURU & crs & crs & crs & crs \\
\hline 57 & ELURU & crs & crs & crs & crs \\
\hline 58 & POLAVARAM & crs & crs & crs & crs \\
\hline 59 & UNDI & crs & crs & crs & crs \\
\hline 60 & UNGUTUR & crs & crs & \\
\hline
\end{tabular}

About 15 percent i.e. 19 out of 127 total AMCs in Coastal region are operating with Increasing Return to Scale(IRS) through out the study period which reveal that these are showing encouraging trend to promote the purpose of AMC subject to additional inputs or resources and support. Infact these AMCs do need encouragement to promote the goal or purpose of AMCs. These are :

Table 2: AMCs with increasing return to scale (IRS) :

\begin{tabular}{|l|l|l|l|l|l|}
\hline \multirow{2}{*}{ S.No. } & \multirow{2}{*}{ Name of AMC } & $2005-06$ & $2006-07$ & $2007-08$ & $2008-09$ \\
\hline & & METURN TO SCALE & \multicolumn{1}{l|}{$\mid$} \\
\hline 2 & MUMMIDIVARAM & irs & irs & irs & irs \\
\hline 2 & CHILAKALURIPET & irs & irs & irs & irs \\
\hline 3 & KROSUR & irs & irs & irs & irs \\
\hline 4 & PONNURU & irs & irs & irs & irs \\
\hline 5 & REPALLE & irs & irs & irs & irs \\
\hline 6 & SATTENAPALLI & irs & irs & irs & irs \\
\hline 7 & VINUKONDA & irs & irs & irs & irs \\
\hline 8 & JAGGAYAPETA & irs & irs & irs & irs \\
\hline 9 & MYLAVARAM & irs & irs & irs & irs \\
\hline 10 & NUZIVUD & irs & irs & irs & irs \\
\hline 11 & RAPUR & irs & irs & irs & irs \\
\hline 12 & MARTUR & irs & irs & irs & irs \\
\hline 13 & PODILI & irs & irs & irs & irs \\
\hline 14 & KANCHILI & irs & irs & irs & irs \\
\hline 15 & PALAKONDA & irs & irs & irs & irs \\
\hline 16 & CHEPURUPALLI & irs & irs & irs & irs \\
\hline 17 & KOTHAVALASA & irs & irs & irs & irs \\
\hline 18 & SALURU & irs & irs & irs & irs \\
\hline 19 & GOPALAPURAM & irs & irs & irs & irs \\
\hline
\end{tabular}

However it is important to note that none of the other AMCs in the Coastal region of Andhra Pradesh is operating with Decreasing Return to Scale(DRS) during the study period which is a encouraging factor with respect to the efficiency of AMCs.

$>$ Only one AMC(Gudivada) is operated with DRS for three years of reference study period. Further it is observed that some of the AMCs are exhibiting dismal performance regarding operational efficiency of the resources, i.e., they are operated with DRS for one or two years of reference period of study which indicates that the resources of these AMCs can be transferred to AMCs operated with IRS. These AMCs are seen in Table 3. 
Table 3 : AMCs with trend of scale during 2005-2009:

\begin{tabular}{|l|l|l|l|l|l|}
\hline \multirow{2}{*}{ S.No. } & \multirow{2}{*}{ Name of AMC } & \multicolumn{2}{l}{ RETURN TO SCALE } \\
\cline { 3 - 6 } & & $2005-06$ & $2006-07$ & $2007-08$ & $2008-09$ \\
\hline 1 & ALLAVARAM & crs & DRS & crs & crs \\
\hline 2 & KOTHAPETA & irs & irs & irs & DRS \\
\hline 3 & PRATHIPADU & crs & crs & DRS & DRS \\
\hline 4 & RAJAHMUNDRY & DRS & crs & DRS & irs \\
\hline 5 & TUNI & DRS & crs & irs & DRS \\
\hline 6 & GUDIVADA & DRS & DRS & irs & DRS \\
\hline 7 & NANDIGAMA & irs & irs & irs & DRS \\
\hline 8 & VUYYURU & irs & irs & irs & DRS \\
\hline 9 & ADDANKI & crs & DRS & DRS & irs \\
\hline 10 & KANDEPI & DRS & crs & irs & DRS \\
\hline 11 & MADDIPADU & DRS & crs & irs & irs \\
\hline 12 & NARASANNAPETA & irs & irs & DRS & DRS \\
\hline 13 & PONDURU & crs & crs & crs & DRS \\
\hline 14 & RAJAM & crs & crs & crs & DRS \\
\hline 15 & SOMPETA & irs & irs & DRS & irs \\
\hline 16 & PARVATHIPURAM & crs & crs & DRS & DRS \\
\hline 17 & ATTILI & crs & crs & DRS & crs \\
\hline 18 & CHINTALAPUDI & irs & irs & irs & DRS \\
\hline 19 & KOVVUR & DRS & crs & irs & DRS \\
\hline 20 & NARSAPURAM & DRS & crs & irs & irs \\
\hline 21 & PENUGONDA & crs & crs & DRS & DRS \\
\hline 22 & TANAKU & crs & DRS & crs & crs \\
\hline
\end{tabular}

It is also noticed that some of the AMCs have shown a shift in the return to scale pattern i.e either from IRS to CRS or vice-versa implying that, there is increased resource use efficiency with reference to the exploitation of resources usage . Hence, these AMCs have shown an increased pace of return to scale. These AMCs are seen in Table 4.

Table 4 : AMCs with trend of CRS and IRS during 2005-2009:

\begin{tabular}{|c|c|c|c|c|c|}
\hline \multirow{2}{*}{ S.No. } & \multirow{2}{*}{ Name of AMC } & \multicolumn{4}{|c|}{ RETURN TO SCALE } \\
\hline & & 2005-06 & 2006-07 & $2007-08$ & 2008-09 \\
\hline 1 & ANAPARTHY & crs & irs & irs & irs \\
\hline 2 & NAGARAM & crs & crs & crs & irs \\
\hline 3 & BAPATLA & irs & irs & irs & crs \\
\hline 4 & IPUR & irs & irs & irs & crs \\
\hline 5 & MACHERLA & crs & irs & crs & irs \\
\hline 6 & MANGALAGIRI & crs & irs & crs & irs \\
\hline 7 & NARSARAOPETA & irs & irs & irs & crs \\
\hline 8 & TENALI & irs & irs & crs & crs \\
\hline 9 & KALIDINDI & irs & crs & crs & crs \\
\hline 10 & MACHILIPATNAM & irs & crs & crs & crs \\
\hline 11 & MOVVA & crs & irs & irs & irs \\
\hline 12 & PAMARRU & crs & crs & crs & irs \\
\hline 13 & TIRUVUR & irs & crs & irs & irs \\
\hline 14 & NAIDUPET & irs & crs & irs & irs \\
\hline 15 & UDAYAGIRI & crs & crs & crs & irs \\
\hline 16 & CHERALA & irs & irs & irs & crs \\
\hline 17 & KAMBAM & crs & crs & crs & irs \\
\hline 18 & AMADALAVALASA & irs & crs & crs & irs \\
\hline 19 & HIRAMANDALAM & crs & crs & crs & irs \\
\hline 20 & PATHAPATNAM & crs & crs & crs & irs \\
\hline 21 & CHODAVARAM & irs & irs & irs & crs \\
\hline 22 & NARSIPATNAM & crs & irs & crs & irs \\
\hline 23 & PADERU & crs & crs & crs & irs \\
\hline 24 & YELAMANCHELLI & irs & irs & crs & irs \\
\hline 25 & PALAKOLLU & crs & irs & irs & irs \\
\hline 26 & TADEPALLIGUDEM & crs & crs & crs & irs \\
\hline
\end{tabular}


PERFORMANCE OF Amcs AT DISTRICT LEVEL : Mean technical efficiency of AMCs in Coastal region district-wise was obtained and shown in table-6 and 7. Interestingly some of the following observations are established.

$>$ In Coastal region more number of efficient AMCs are identified compared to inefficient AMCs which reveal that the purpose of AMCs are significant in this part of Andhra Pradesh(table-7).

$>$ Further it is interesting and encouraging to note that number of efficient AMCs increased from the financial year 2005-06 to 2008-09 which is a positive growth and trend for the promotion of AMCs activity as per the intention of Government scheme in the Coastal region of Andhra Pradesh(table-7).

Among selected districts (table-6), East Godavari district had exhibited highest mean scale efficiency for three years except in the year 2007-08 and Nellore district is having highest mean scale efficiency for one years i.e., 2007-08. The district with least mean scale efficiency throughout the reference study period is Guntur.

The informal discussions held with AMC Officials revealed the following interesting points for this heartening performance:

- Farmers are showing positive attitude for transacting their produce in the AMCs compared to local markets on account of the competitive price being realized in the AMCs.

- Strengthening of infrastructure in the market yards like grading, processing, marketing information network, storage facilities etc.

- More encouragement by the Government in the form of implementing pledge loan scheme, Rythu Bandhu Padhakam etc.

- $\quad$ Regulation of marketing practices and marketing costs.

\section{Conclusions}

The analyses reveal that nearly 62 percent of the overall 127 AMC in Coastal region seen to be performing optimally(efficiently fulfilling the purpose) balancing the resources. However still 38 percent of the overall 127 AMCs, the efficiency is behind optimal level. Among this, 23 percent of AMCs are not achieving the best performance due to lack of availability of adequate resources while improvement can be established with augmenting adequate resources(inputs). However, other 15 percent of AMCs do not perform efficiently due to lack of motivation since the resources are under utilized and does not exhibit the fulfillment of optimal performance inspite of adequate resources. Therefore the study identifies that the resources which are unutilized in some of the AMCs can be distributed to those which are lagging behind due to scarcity of resources to promote and strengthen the overall activity of AMC performance in this region. This will promote 90 percent of AMCs to achieve optimal performance within the region and to participate in the wellbeing of farming community as per the intention of the Government support.

\section{References}

[1] Banker, R.D., Charnes, A. \& Cooper, W.W. (1984). Some models for estimating technical and scale inefficiencies in data envelopment analysis. Management Science, 30, 1078-1092.

[2] Boussofiane, A., Dyson, R.G. \& Thanassoulis, E. (1992). Applied data envelopment analysis. European Journal of Operations Research, 52, 1-15.

[3] Charnes, A., Cooper, W.W., \& Rhodes, E. (1978). Measuring the efficiency of decision making units. European Journal of Operations Research, 2, 429-444.

[4] Coelli, T., Rao, D. \& Battese, G. (1998). An introduction to efficiency and productivity analysis. Kluwer Academic Publisher group, London.

[5] Cooper, W.W., Seiford, L.M. \& Tone, K. (2004). Data Envelopment Analysis, a comprehensive text with models. Kluwer Academic Publisher group, London.

[6] Fried, H., Lovell, C., Schmidt, S. \& Yaisawarng, S. (2002). Accounting for environmental effects and statistical noise in data envelopment analysis. Journal of Productivity Analysis, 17, 157-174.

[7] Rogers, M. (1998). The definition and measurement of productivity. The university of Melbourne, Australia; Melbourne institute of applied economics and social research.

[8] Zhu, J. (2003). Quantitative models for performance evaluation and benchmarking, Kluwer Academic Publishers group, London.

[9] www.agmarketnet.nic.in -Website. 


\begin{tabular}{|c|c|c|c|c|c|c|c|c|c|c|c|c|c|c|c|c|c|}
\hline \multirow{2}{*}{ S.No. } & \multirow{2}{*}{ Name of AMC } & \multicolumn{4}{|c|}{$2005-06$} & \multicolumn{4}{|c|}{$2006-07$} & \multicolumn{4}{|c|}{$2007-08$} & \multicolumn{4}{|c|}{$2008-09$} \\
\hline & & CRS & VRS & Scale & RTS & CRS & VRS & Scale & RTS & CRS & VRS & Scale & RTS & CRS & VRS & Scale & RTS \\
\hline 1 & ALAMCRU & 1 & 1 & 1 & $c r s$ & 1 & 1 & 1 & crs & 1 & 1 & 1 & $\mathrm{Crs}$ & 1 & 1 & 1 & crs \\
\hline 2 & ALLAVARAM & 1 & 1 & 1 & $\mathrm{crs}$ & 0.9974 & 1 & 0.9974 & DRS & 1 & 1 & 1 & $\mathrm{crs}$ & 1 & 1 & 1 & crs \\
\hline 3 & AMBAIPETA & 1 & 1 & 1 & $\mathrm{crs}$ & 1 & 1 & 1 & crs & 1 & 1 & 1 & crs & 1 & 1 & 1 & crs \\
\hline 4 & ANAPARTHY & 1 & 1 & 1 & $\mathrm{crs}$ & 0.8619 & 1 & 0.8619 & irs & 0.8559 & 1 & 0.8559 & irs & 0.922 & 1 & 0.922 & irs \\
\hline 5 & JAGGAMPETA & 1 & 1 & 1 & crs & 1 & 1 & 1 & crs & 1 & 1 & 1 & crs & 1 & 1 & 1 & crs \\
\hline 6 & KAKMNADA & 1 & 1 & 1 & $c r s$ & 1 & 1 & 1 & $\mathrm{crs}$ & 1 & 1 & 1 & $\mathrm{Crs}$ & 1 & 1 & 1 & $\mathrm{crs}$ \\
\hline 7 & KOTHAPETA & 0.7999 & 0.8622 & 0.9277 & irs & 0.8656 & 0.894 & 0.9683 & irs & 0.8672 & 0.8691 & 0.9978 & irs & 0.9618 & 1 & 0.9618 & DRS \\
\hline 8 & MUMMIDIVARAM & 0.717 & 1 & 0.717 & irs & 0.7908 & 1 & 0.7908 & irs & 0.701 & 0.9792 & 0.7159 & irs & 0.5224 & 1 & 0.5224 & irs \\
\hline 9 & NAGARAM & 1 & 1 & 1 & $c r s$ & 1 & 1 & 1 & $\mathrm{crs}$ & 1 & 1 & 1 & $\mathrm{crs}$ & 0.5529 & 0.699 & 0.7909 & irs \\
\hline 10 & PEDDAPURAM & 1 & 1 & 1 & $\mathrm{crs}$ & 1 & 1 & 1 & crs & 1 & 1 & 1 & crs & 1 & 1 & 1 & crs \\
\hline 11 & PITHAPURAM & 1 & 1 & 1 & $c r s$ & 1 & 1 & 1 & $c r s$ & 1 & 1 & 1 & $\mathrm{crs}$ & 1 & 1 & 1 & crs \\
\hline 12 & PRATHIIPADU & 1 & 1 & 1 & $\mathrm{crs}$ & 1 & 1 & 1 & crs & 0.9299 & 1 & 0.9299 & DRS & 0.8833 & 0.9866 & 0.8953 & DRS \\
\hline 13 & RAJAHMUNDRY & 0.9078 & 0.9482 & 0.9574 & DRS & 1 & 1 & 1 & $\mathrm{crs}$ & 0.7565 & 0.7674 & 0.9858 & DRS & 0.6691 & 0.7083 & 0.9446 & irs \\
\hline 14 & RAJOLE & 1 & 1 & 1 & $c r s$ & 1 & 1 & 1 & $\mathrm{crs}$ & 1 & 1 & 1 & crs & 1 & 1 & 1 & crs \\
\hline 15 & Ramachandrapuram & 1 & 1 & 1 & $\mathrm{crs}$ & 1 & 1 & 1 & $\mathrm{crs}$ & 1 & 1 & 1 & $\mathrm{crs}$ & 1 & 1 & 1 & $\mathrm{crs}$ \\
\hline 16 & SAMARLAKOTA & 1 & 1 & 1 & $c r s$ & 1 & 1 & 1 & $\mathrm{crs}$ & 1 & 1 & 1 & crs & 1 & 1 & 1 & crs \\
\hline 17 & SAMPARA & 1 & 1 & 1 & $c r s$ & 1 & 1 & 1 & $\mathrm{crs}$ & 1 & 1 & 1 & $\mathrm{crs}$ & 1 & 1 & 1 & $c r s$ \\
\hline 18 & TALLAREVU & 1 & 1 & 1 & $c r s$ & 1 & 1 & 1 & $\mathrm{crs}$ & 1 & 1 & 1 & $\mathrm{crs}$ & 1 & 1 & 1 & $c r s$ \\
\hline 19 & TUNI & 0.8322 & 0.9067 & 0.9178 & DRS & 1 & 1 & 1 & crs & 0.7366 & 0.769 & 0.9579 & irs & 0.9842 & 1 & 0.9842 & DRS \\
\hline 20 & BAPATLA & 0.9621 & 1 & 0.9621 & irs & 0.8934 & 1 & 0.8934 & irs & 0.9611 & 1 & 0.9611 & irs & 1 & 1 & 1 & crs \\
\hline 21 & CHILAKALURIPET & 0.5898 & 1 & 0.5898 & irs & 0.9574 & 1 & 0.9574 & irs & 0.7779 & 1 & 0.7779 & irs & 0.5637 & 1 & 0.5637 & irs \\
\hline 22 & DUGGRALA & 1 & 1 & 1 & crs & 1 & 1 & 1 & crs & 1 & 1 & 1 & $\mathrm{crs}$ & 1 & 1 & 1 & crs \\
\hline 23 & GUNTUR & 1 & 1 & 1 & $c r s$ & 1 & 1 & 1 & $\mathrm{crs}$ & 1 & 1 & 1 & $\mathrm{crs}$ & 1 & 1 & 1 & $c r s$ \\
\hline 24 & IPUR & 0.5863 & 1 & 0.5863 & irs & 0.5949 & 1 & 0.5949 & irs & 0.612 & 1 & 0.612 & irs & 1 & 1 & 1 & crs \\
\hline 25 & KROSUR & 0.5354 & 1 & 0.5354 & irs & 0.685 & 1 & 0.685 & irs & 0.8138 & 1 & 0.8138 & irs & 0.6728 & 1 & 0.6728 & irs \\
\hline 26 & KUCHNAPUDI & 1 & 1 & 1 & $\mathrm{crs}$ & 1 & 1 & 1 & crs & 1 & 1 & 1 & crs & 1 & 1 & 1 & crs \\
\hline 27 & MACHERLA & 1 & 1 & 1 & $\mathrm{crs}$ & 0.9473 & 1 & 0.9473 & irs & 1 & 1 & 1 & $\mathrm{Crs}$ & 0.8835 & 1 & 0.8835 & irs \\
\hline 28 & MANGALAGIRI & 1 & 1 & 1 & $\mathrm{crs}$ & 0.6777 & 1 & 0.6777 & irs & 1 & 1 & 1 & crs & 0.5562 & 1 & 0.5562 & irs \\
\hline 29 & NARSARAOPETA & 0.4447 & 1 & 0.4447 & irs & 0.6014 & 1 & 0.6014 & irs & 0.7067 & 1 & 0.7067 & irs & 1 & 1 & 1 & $c r s$ \\
\hline 30 & PIDIGURALLA & 1 & 1 & 1 & $c r s$ & 1 & 1 & 1 & $c r s$ & 1 & 1 & 1 & crs & 1 & 1 & 1 & $c r s$ \\
\hline 31 & PONNURU & 0.8957 & 1 & 0.8957 & irs & 0.8478 & 1 & 0.8478 & irs & 0.8796 & 1 & 0.8796 & irs & 0.9044 & 1 & 0.9044 & irs \\
\hline 32 & REPALLE & 0.5817 & 1 & 0.5817 & irs & 0.667 & 1 & 0.667 & irs & 0.6338 & 1 & 0.6338 & irs & 0.5306 & 1 & 0.5306 & irs \\
\hline 33 & ROMPICHERLA & 1 & 1 & 1 & $\mathrm{crs}$ & 1 & 1 & 1 & crs & 1 & 1 & 1 & crs & 1 & 1 & 1 & crs \\
\hline 34 & SATTENAPALLI & 0.5724 & 1 & 0.5724 & irs & 0.889 & 1 & 0.889 & irs & 0.8841 & 1 & 0.8841 & irs & 0.5925 & 1 & 0.5925 & irs \\
\hline
\end{tabular}

\begin{tabular}{|c|c|c|c|c|c|c|c|c|c|c|c|c|c|c|c|c|c|}
\hline 35 & TADIKONDA & 1 & 1 & 1 & $c r s$ & 1 & 1 & 1 & crs & 1 & 1 & 1 & crs & 1 & 1 & 1 & crs \\
\hline 36 & TENALI & 0.9718 & 1 & 0.9718 & irs & 0.9717 & 1 & 0.9717 & irs & 1 & 1 & 1 & crs & 1 & 1 & 1 & crs \\
\hline 37 & VINUKONDA & 0.4933 & 1 & 0.4933 & irs & 0.5839 & 1 & 0.5839 & irs & 0.6859 & 1 & 0.6859 & irs & 0.587 & 1 & 0.587 & irs \\
\hline 38 & AVANGADDA & 1 & 1 & 1 & $\mathrm{crs}$ & 1 & 1 & 1 & crs & 1 & 1 & 1 & $\mathrm{crs}$ & 1 & 1 & 1 & $\mathrm{crs}$ \\
\hline 39 & GANNAVARAM & 1 & 1 & 1 & $c r s$ & 1 & 1 & 1 & crs & 1 & 1 & 1 & $\mathrm{crs}$ & 1 & 1 & 1 & $c r s$ \\
\hline 40 & GUDIVADA & 0.761 & 0.7672 & 0.992 & DRS & 0.7653 & 0.7844 & 0.9756 & DRS & 0.7502 & 0.7506 & 0.9995 & irs & 0.8399 & 1 & 0.8399 & DRS \\
\hline 41 & JAGGAYAPETA & 0.5004 & 0.7741 & 0.6465 & irs & 0.4914 & 0.7735 & 0.6352 & irs & 0.439 & 0.8376 & 0.5241 & irs & 0.5203 & 0.7495 & 0.6942 & irs \\
\hline 42 & KAIKALUR & 1 & 1 & 1 & $\mathrm{crs}$ & 1 & 1 & 1 & crs & 1 & 1 & 1 & $\mathrm{crs}$ & 1 & 1 & 1 & crs \\
\hline 43 & KALDDNDI & 0.9727 & 1 & 0.9727 & irs & 1 & 1 & 1 & crs & 1 & 1 & 1 & $\mathrm{crs}$ & 1 & 1 & 1 & $\mathrm{crs}$ \\
\hline 44 & KANCHIKACHERLA & 1 & 1 & 1 & $\mathrm{crs}$ & 1 & 1 & 1 & crs & 1 & 1 & 1 & crs & 1 & 1 & 1 & $c r s$ \\
\hline 45 & MACHIIIPATNAM & 0.9758 & 1 & 0.9758 & irs & 1 & 1 & 1 & crs & 1 & 1 & 1 & $\mathrm{crs}$ & 1 & 1 & 1 & crs \\
\hline 46 & MALLESWARAM & 1 & 1 & 1 & crs & 1 & 1 & 1 & crs & 1 & 1 & 1 & crs & 1 & 1 & 1 & crs \\
\hline 47 & MOVvA & 1 & 1 & 1 & $\mathrm{crs}$ & 0.6703 & 0.9599 & 0.6983 & irs & 0.7452 & 0.9538 & 0.7813 & irs & 0.7157 & 0.8501 & 0.8419 & irs \\
\hline 48 & MYLAVARAM & 0.7445 & 0.8264 & 0.9009 & irs & 0.7525 & 0.8443 & 0.8913 & irs & 0.6616 & 0.8624 & 0.7672 & irs & 0.7551 & 0.7694 & 0.9814 & irs \\
\hline 49 & NANDIGAMA & 0.6968 & 0.7465 & 0.9334 & irs & 0.8815 & 0.8869 & 0.9939 & irs & 0.8195 & 0.8644 & 0.948 & irs & 0.9361 & 1 & 0.9361 & DRS \\
\hline 50 & NUZTVUD & 0.5448 & 0.7982 & 0.6826 & irs & 0.4738 & 0.8143 & 0.5818 & irs & 0.4421 & 0.8104 & 0.5455 & irs & 0.4694 & 0.7242 & 0.6482 & irs \\
\hline 51 & PAMAARU & 1 & 1 & 1 & $\mathrm{crs}$ & 1 & 1 & 1 & crs & 1 & 1 & 1 & crs & 0.7894 & 1 & 0.7894 & irs \\
\hline 52 & TRUVVR & 0.6697 & 0.7595 & 0.8817 & irs & 1 & 1 & 1 & crs & 0.747 & \begin{tabular}{|l|l|}
0.7977 \\
\end{tabular} & 0.9364 & irs & 0.8579 & 0.8811 & 0.9736 & irs \\
\hline 53 & VIAYAWADA & 1 & 1 & 1 & crs & 1 & 1 & 1 & crs & 1 & 1 & 1 & crs & 1 & 1 & 1 & crs \\
\hline 54 & VUYYURU & 0.8876 & 0.919 & 0.9659 & irs & 0.9342 & 0.9435 & 0.9901 & irs & 0.8734 & 0.9182 & 0.9513 & irs & 0.9572 & 0.9762 & 0.9805 & DRS \\
\hline 55 & ATMAKUR & 1 & 1 & 1 & $c r s$ & 1 & 1 & 1 & crs & 1 & 1 & 1 & crs & 1 & 1 & 1 & crs \\
\hline 56 & GUDUR & 1 & 1 & 1 & $c r s$ & 1 & 1 & 1 & crs & 1 & 1 & 1 & crs & 1 & 1 & 1 & $\mathrm{Crs}$ \\
\hline 57 & KAVALI & 1 & 1 & 1 & $\mathrm{Crs}$ & 1 & 1 & 1 & crs & 1 & 1 & 1 & $\mathrm{crs}$ & 1 & 1 & 1 & $\mathrm{Crs}$ \\
\hline 58 & KOVVUR & 1 & 1 & 1 & crs & 1 & 1 & 1 & crs & 1 & 1 & 1 & crs & 1 & 1 & 1 & crs \\
\hline 59 & NAIDUPET & 0.9361 & 1 & 0.9361 & irs & 1 & 1 & 1 & crs & 0.9129 & 1 & 0.9129 & irs & 0.6894 & 1 & 0.6894 & irs \\
\hline 60 & NELLORE & 1 & 1 & 1 & $\mathrm{Crs}$ & 1 & 1 & 1 & crs & 1 & 1 & 1 & crs & 1 & 1 & 1 & $\mathrm{crs}$ \\
\hline 61 & RAPUR & 0.6159 & 0.8434 & 0.7303 & irs & 0.8162 & 0.9664 & 0.8445 & irs & 0.7341 & 0.9061 & 0.8102 & irs & 0.632 & 0.8085 & 0.7817 & irs \\
\hline 62 & SULLUR PET & 1 & 1 & 1 & $\mathrm{crs}$ & 1 & 1 & 1 & crs & 1 & 1 & 1 & crs & 1 & 1 & 1 & crs \\
\hline 63 & UDAYAGRI & 1 & 1 & 1 & $c r s$ & 1 & 1 & 1 & crs & 1 & 1 & 1 & $\mathrm{crs}$ & 0.8037 & 0.9053 & 0.8878 & irs \\
\hline 64 & VAKADU & 1 & 1 & 1 & $\mathrm{crs}$ & 1 & 1 & 1 & crs & 1 & 1 & 1 & crs & 1 & 1 & 1 & crs \\
\hline 65 & VENKATAGRI & 1 & 1 & 1 & $c r s$ & 1 & 1 & 1 & crs & 1 & 1 & 1 & crs & 1 & 1 & 1 & $\mathrm{crs}$ \\
\hline 66 & ADDANKI & 1 & 1 & 1 & $\mathrm{crs}$ & 0.9749 & 0.9775 & 0.9973 & DRS & 0.9882 & 1 & 0.9882 & DRS & 0.9537 & 0.9651 & 0.9882 & irs \\
\hline 67 & CHERALA & 0.9029 & 0.9043 & 0.9984 & irs & 0.7549 & 0.7908 & 0.9546 & irs & 0.7305 & 0.7708 & 0.9477 & irs & 1 & 1 & 1 & $\mathrm{crs}$ \\
\hline 68 & DARSI & 1 & 1 & 1 & $\mathrm{crs}$ & 1 & 1 & 1 & crs & 1 & 1 & 1 & crs & 1 & 1 & 1 & $\mathrm{Crs}$ \\
\hline 69 & GIDDALUR & 1 & 1 & 1 & crs & 1 & 1 & 1 & crs & 1 & 1 & 1 & crs & 1 & 1 & 1 & crs \\
\hline 70 & KAMBAM & 1 & 1 & 1 & $\mathrm{crs}$ & 1 & 1 & 1 & crs & 1 & 1 & 1 & $\mathrm{crs}$ & 0.7293 & 1 & 0.7293 & irs \\
\hline
\end{tabular}




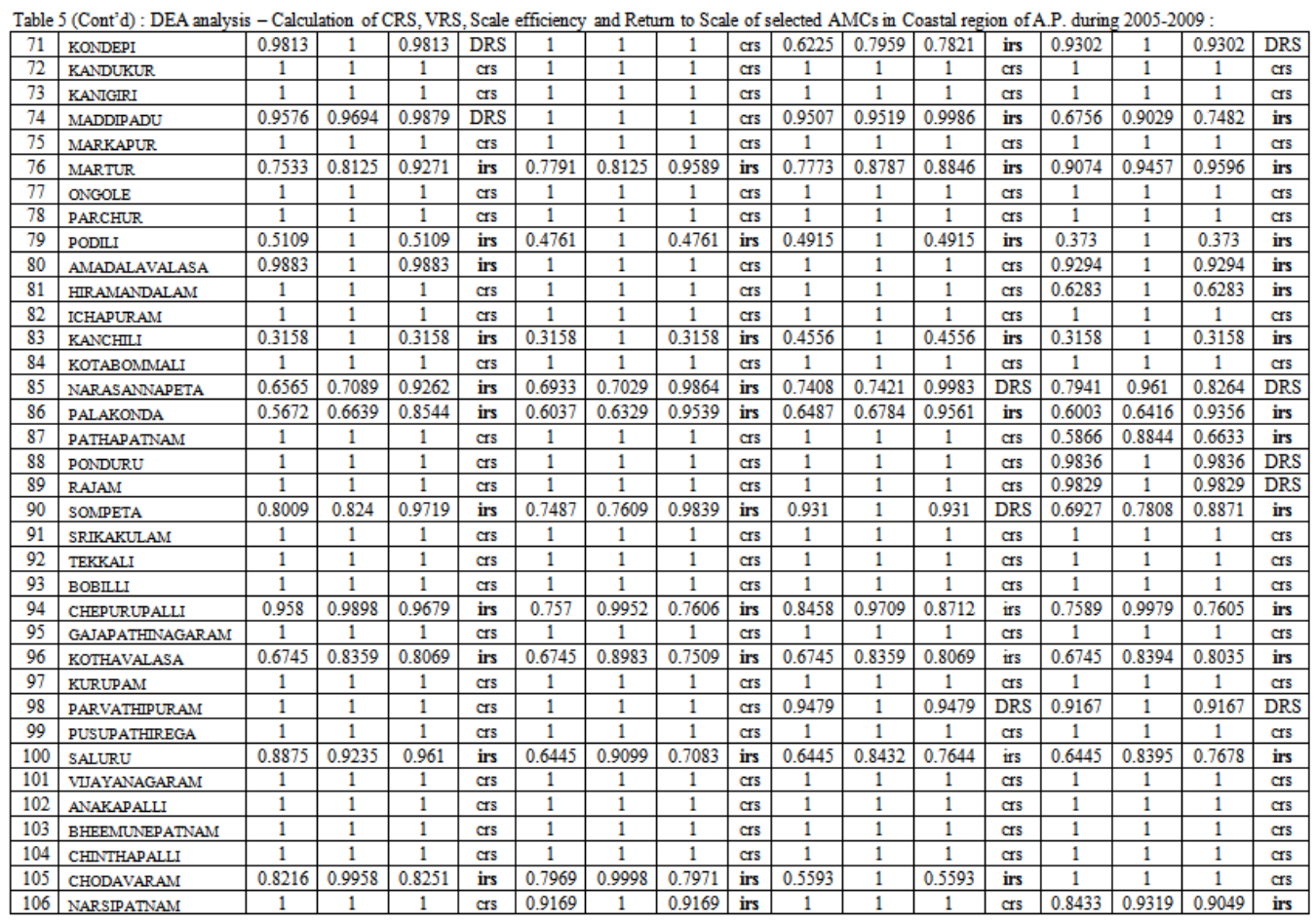

\begin{tabular}{|c|c|c|c|c|c|c|c|c|c|c|c|c|c|c|c|c|c|}
\hline 107 & PADERU & 1 & 1 & 1 & $\mathrm{crs}$ & 1 & 1 & 1 & $\mathrm{crs}$ & 1 & 1 & 1 & $\mathrm{crs}$ & 0.5359 & 0.9912 & 0.5407 & irs \\
\hline 108 & \begin{tabular}{|l|} 
VISAKAPATNAMM \\
\end{tabular} & 1 & 1 & 1 & $\mathrm{crs}$ & 1 & 1 & 1 & $\mathrm{crs}$ & 1 & 1 & 1 & $\mathrm{Crs}$ & 1 & 1 & 1 & $c r s$ \\
\hline 109 & \begin{tabular}{|l|} 
YEL_ANANCHELLI \\
\end{tabular} & 0.8226 & 1 & 0.8226 & irs & 0.8468 & 1 & 0.8468 & irs & 1 & 1 & 1 & $c r s$ & 0.9618 & 1 & 0.9618 & irs \\
\hline 110 & ACHANTA & 1 & 1 & 1 & $c r s$ & 1 & 1 & 1 & $\mathrm{crs}$ & 1 & 1 & 1 & $c r s$ & 1 & 1 & 1 & crs \\
\hline 111 & AKIVIDU & 1 & 1 & 1 & crs & 1 & 1 & + & $\mathrm{crs}$ & 1 & 1 & 1 & $c r s$ & 1 & 1 & 1 & crs \\
\hline 112 & ATTILI & 1 & 1 & 1 & $c r s$ & 1 & 1 & 1 & $\mathrm{crs}$ & 0.995 & 1 & 0.995 & DRS & 1 & 1 & 1 & crs \\
\hline 113 & BHEMADOLU & 1 & 1 & 1 & crs & 1 & 1 & 1 & $\mathrm{crs}$ & 1 & 1 & 1 & $\mathrm{crs}$ & 1 & 1 & 1 & $\mathrm{crs}$ \\
\hline 114 & BHIVARAM & 1 & 1 & 1 & crs & 1 & 1 & 1 & $\mathrm{crs}$ & 1 & 1 & 1 & crs & 1 & 1 & 1 & $\mathrm{crs}$ \\
\hline 115 & $\mathrm{CHMN}$ & 0.7999 & 0.8623 & 0.9277 & irs & 0.8623 & 0.8889 & 0.9701 & irs & 0.8672 & 0.8691 & 0.9978 & irs & 0.9618 & 1 & 0.9618 & DRS \\
\hline 116 & DENDLUR & 1 & 1 & 1 & $\mathrm{crs}$ & 7 & 1 & 4 & $\mathrm{crs}$ & 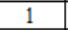 & 1 & 1 & crs & 1 & 1 & 1 & crs \\
\hline 117 & ELURU & 1 & 1 & 1 & crs & 1 & 1 & 1 & $\mathrm{crs}$ & 1 & 1 & 1 & crs & 1 & 1 & 1 & $\mathrm{crs}$ \\
\hline 118 & GOPALAPURAM & 0.7165 & 1 & 0.7165 & irs & 0.7888 & 1 & 0.7888 & irs & 0.6746 & 0.9792 & 0.6889 & irs & 0.5224 & 1 & 0.5224 & irs \\
\hline 119 & KOVVUR & 0.832 & 0.9063 & 0.918 & DRS & 1 & 1 & 1 & $c r s$ & 0.7366 & 0.769 & 0.9579 & irs & 0.9842 & 1 & 0.9842 & DRS \\
\hline 120 & NARSAPURAM & 0.9076 & 0.9472 & 0.9582 & DRS & 1 & 1 & 1 & $c r s$ & 0.7418 & 0.7422 & 0.9995 & irs & 0.6691 & 0.7083 & 0.9446 & irs \\
\hline 121 & PALAKOLLU & 1 & 1 & 1 & $c r s$ & 0.8619 & 1 & 0.8619 & irs & 0.8559 & 1 & 0.8559 & irs & 0.922 & 1 & 0.922 & irs \\
\hline 122 & PENUGONDA & 1 & 1 & 1 & $c r s$ & 1 & 1 & 1 & $\mathrm{crs}$ & 0.916 & 1 & 0.916 & DRS & 0.8833 & 0.9866 & 0.8953 & DRS \\
\hline 123 & POLAVARAM & 1 & 1 & 1 & crs & 1 & 1 & 1 & $\mathrm{crs}$ & 1 & 1 & 1 & $\mathrm{crs}$ & 1 & 1 & 1 & $\mathrm{crs}$ \\
\hline 124 & TADEPALI & 1 & 1 & 1 & $\mathrm{crs}$ & 1 & 1 & 1 & $\mathrm{crs}$ & 1 & & 1 & $\mathrm{crs}$ & 0.5529 & 0.699 & 0.7909 & irs \\
\hline 125 & TANAKU & 1 & 1 & 1 & $\mathrm{crs}$ & 0.9974 & 1 & 0.9974 & DRS & 1 & 1 & 1 & $c r s$ & 1 & 1 & 1 & $\mathrm{crs}$ \\
\hline 126 & UNDI & 1 & 1 & 1 & $c r s$ & 1 & 1 & 1 & $\mathrm{crs}$ & 1 & 1 & 1 & $\mathrm{crs}$ & 1 & 1 & 1 & $\mathrm{crs}$ \\
\hline 127 & UNGUT & 1 & 1 & 1 & crs & 1 & 1 & 1 & $\mathrm{crs}$ & 1 & 1 & 1 & $\mathrm{crs}$ & 1 & 1 & 1 & $\mathrm{crs}$ \\
\hline & MEA & 0.9138 & 0.9724 & 0.9381 & & 0.9221 & 0.9782 & 0.9415 & & 0.9112 & 0.9678 & 0.9399 & & 0.8871 & 0.9696 & 0.9127 & \\
\hline & S.D. & 0.1572 & 0.069 & 0.1371 & & 0.1436 & 0.064 & 0.1265 & & 0.1453 & 0.0737 & 0.1221 & & 0.1736 & 0.0782 & 0.1505 & \\
\hline
\end{tabular}

Table 6: Mean Technical Efficiencies - District-wise and Year-wise for AMCs in Coastal region of A.P. during 2005-2009

\begin{tabular}{|c|c|c|c|c|c|c|c|c|c|c|c|c|}
\hline \multirow{2}{*}{ District } & \multicolumn{3}{|c|}{$2005-06$} & \multicolumn{3}{|c|}{$2006-07$} & \multicolumn{3}{c|}{$2007-08$} & \multicolumn{3}{|c|}{$2008-09$} \\
\cline { 2 - 14 } & CRS & VRS & SCALE & CRS & VRS & SCALE & CRS & VRS & SCALE & CRS & VRS & SCALE \\
\hline EG & 0.9609 & 0.9851 & 0.9747 & 0.9745 & 0.9944 & 0.9799 & 0.9393 & 0.9676 & 0.9707 & 0.9208 & 0.9681 & 0.9485 \\
\hline Guntur & 0.813 & 1 & 0.813 & 0.8509 & 1 & 0.8509 & 0.8864 & 1 & 0.8864 & 0.8495 & 1 & 0.8495 \\
\hline Krishna & 0.8678 & 0.9171 & 0.9383 & 0.8805 & 0.9416 & 0.9274 & 0.8516 & 0.9291 & 0.909 & 0.873 & 0.9383 & 0.9227 \\
\hline Nellore & 0.9593 & 0.9858 & 0.9697 & 0.9833 & 0.9969 & 0.9859 & 0.9679 & 0.9915 & 0.9748 & 0.9205 & 0.974 & 0.9417 \\
\hline PRKS & 0.9361 & 0.9776 & 0.9575 & 0.9275 & 0.9701 & 0.9562 & 0.8972 & 0.957 & 0.9352 & 0.8978 & 0.9867 & 0.9092 \\
\hline SKLM & 0.8714 & 0.9382 & 0.9274 & 0.874 & 0.9305 & 0.9415 & 0.9059 & 0.9554 & 0.9493 & 0.8087 & 0.9437 & 0.8579 \\
\hline VJNR & 0.9467 & 0.9721 & 0.9706 & 0.8973 & 0.9782 & 0.9133 & 0.9014 & 0.9611 & 0.9323 & 0.8883 & 0.9641 & 0.9165 \\
\hline VSKP & 0.9555 & 0.9995 & 0.956 & 0.9451 & 1 & 0.9451 & 0.9449 & 1 & 0.9449 & 0.9176 & 0.9904 & 0.9259 \\
\hline WG & 0.9587 & 0.9842 & 0.9734 & 0.9728 & 0.9938 & 0.9788 & 0.9326 & 0.9644 & 0.9673 & 0.9164 & 0.9663 & 0.9456 \\
\hline
\end{tabular}

Note : EG=East Godavari, PRKS=Prakasam, SKLM=Srikakulam, VJNR=Viiayanagaram, VSKP=Visakapatnam, WG=West Godavari 


Table 7: AMCs along with efficiencies and Statistical analysis in Coastal region of A.P. during 2005-2009:
\begin{tabular}{|l|c|c|c|c|c|c|c|c|c|c|c|c|}
\hline Description & \multicolumn{3}{|c|}{$2005-06$} & \multicolumn{3}{|c|}{$2006-07$} & \multicolumn{3}{|c|}{$2007-08$} & \multicolumn{3}{c|}{$2008-09$} \\
\cline { 2 - 13 } & CRS & VRS & SCALE & CRS & VRS & SCALE & CRS & VRS & SCALE & CRS & VRS & SCALE \\
\hline $\begin{array}{l}\text { No. of } \\
\text { AMCs } \\
\text { evaluated }\end{array}$ & 127 & 127 & 127 & 127 & 128 & 127 & 127 & 127 & 128 & 127 & 12 & 127 \\
\hline $\begin{array}{l}\text { No. of } \\
\text { efficient } \\
\text { AMCs }\end{array}$ & 83 & 103 & 83 & 85 & 107 & 85 & 80 & 101 & 80 & 71 & 101 & 71 \\
\hline $\begin{array}{l}\text { No. of } \\
\text { Inefficient } \\
\text { AMCs }\end{array}$ & 44 & 24 & 44 & 42 & 20 & 42 & 47 & 26 & 47 & 56 & 26 & 56 \\
\hline $\begin{array}{l}\text { Mean } \\
\text { Score }\end{array}$ & 0.9138 & 0.9724 & 0.9381 & 0.9221 & 0.9782 & 0.9415 & 0.9112 & 0.9678 & 0.9399 & 0.8871 & 0.9696 & 0.9127 \\
\hline $\begin{array}{l}\text { Standard } \\
\text { Deviation }\end{array}$ & 0.1572 & 0.069 & 0.1371 & 0.1436 & 0.064 & 0.1265 & 0.1453 & 0.0737 & 0.1221 & 0.1736 & 0.0782 & 0.1505 \\
\hline $\begin{array}{l}\text { Maximum } \\
\text { Score }\end{array}$ & 1.0000 & 1.0000 & 1.0000 & 1.0000 & 1.0000 & 1.0000 & 1.0000 & 1.0000 & 1.0000 & 1.0000 & 1.0000 & 1.0000 \\
\hline $\begin{array}{l}\text { Minimum } \\
\text { Score }\end{array}$ & 0.3158 & 0.6639 & 0.3158 & 0.3158 & 0.6329 & 0.3158 & 0.4390 & 06784 & 0.4556 & 0.3158 & 0.6990 & 0.3158 \\
\hline
\end{tabular}

